\section{Reflexão bioética sobre a priorização e o racionamento de cuidados de saúde: entre a utilidade social e a eqüidade}

\author{
Bioethics reflection on prioritization and rationing \\ of health care: between social utility and equity
}

1 Faculdade de Saúde Pública, Universidade de São Paulo, São Paulo, Brasil.

Correspondência

P. A. C. Fortes

Faculdade de Saúde Pública Universidade de São Paulo.

Av. Dr. Arnaldo 715

São Paulo, SP

01246-904, Brasil.

pacfusp@usp.br

\section{Abstract}

Since health needs outweigh the available resources, choices are imperative. It is thus necessary to set limits, criteria, and standards in order to prioritize the supply, the recipients, and the services to be provided. Ethical alternatives are discussed for the prioritization and rationing of health care, focusing on the principles of equity and social utility.

Bioethics; Resource Allocation; Equity in Health

\section{Introdução}

É a partir dos anos 70 que se inicia a reflexão sobre o estabelecimento de prioridades e mesmo da possibilidade de racionamento de cuidados de saúde nos diversos tipos de sistemas públicos de saúde contemporâneos, os quais têm utilizado medidas, técnicas e instrumentos racionalizadores dos recursos e dos custos cada vez mais crescentes. Isso se deve, fundamentalmente, a uma série variada de fatores, dentre outros, a urbanização crescente, o incremento das doenças crônico-degenerativas, o envelhecimento populacional, as novas concepções sobre o processo saúde-doença, a medicalização da sociedade, a universalização dos cuidados de saúde, as mudanças de costumes e a crescente incorporação tecnológica.

Disso resulta ser preciso que sejam estabelecidos limites, critérios e parâmetros para se priorizar o que vai ser ofertado e a quem os serviços e os cuidados de saúde serão oferecidos. As decisões neste campo envolvem a ideologia e os valores morais de uma determinada sociedade, além de fatores políticos, econômicos, culturais e legais. Cabe lembrar que as decisões políticas, para serem eficazes, têm de levar em conta os valores e princípios éticos prevalentes na sociedade.

Considerando que as necessidades de saúde são mais amplas que os recursos disponíveis, escolhas têm de ser feitas, não há como escapar de realizá-las. É difícil aceitar uma posição 
extremada, como a emitida por Edmond Cahn, que propugnava o acatamento daquilo que denominaram de "ética dos últimos dias". Segundo essa orientação, tendo as pessoas igual valor e, em não havendo recursos para todos, não se deveria optar por ninguém, pois o homem não poderia ser um substituto da divindade nesta decisão 1 .

Contudo a realidade sanitária não torna essa opção viável, pois há recursos para os cuidados de saúde, ainda que insuficientes, resultando em uma obrigação moral de disponibilizá-los. Devese, portanto, decidir quais as necessidades que devem ser priorizadas e/ou racionadas, escolher quem vai ter oportunidade de continuar a viver, às vezes quem vai morrer, ou mesmo, quem vai ter suas necessidades de saúde atendidas em primeiro lugar. Isso tudo nos leva à reflexão ética sobre o tema.

A ética é um dos instrumentos sociais que visa a contribuir para a manutenção da convivência social. Objetiva harmonizar os interesses individuais e os interesses coletivos. Instrumento social criado para orientar aquilo que se deve fazer para se conseguir uma convivência social feliz e justa 2 .

A ética nos fala de valores, princípios e normas que servem de base para o comportamento humano; é o refletir, argumentar e fornecer justificativas racionais para as escolhas e tomadas de decisões morais em casos e situações concretas ${ }^{3}$.

No campo da saúde temos a bioética, que a partir dos anos 80 vem enfocando problemas relacionados à coletividade, como o acesso aos serviços de saúde, a distribuição e priorização de recursos escassos, assim como a responsabilidade individual e coletiva sobre a assistência à saúde e a questão da priorização de recursos escassos 4.

O papel da reflexão bioética nesse campo é importante, como ressaltado por Momberg 5 (p. 78), da Organização Pan-Americana da Saúde (OPAS), quando afirma de maneira contundente, que "os fundamentos da economia não contribuem para a solução de certos problemas que se apresentam freqüentemente em saúde", como por exemplo, conciliar os interesses individuais com os da sociedade.

\section{Priorização e racionamento de cuidados de saúde no Brasil}

Racionamento de serviços ou cuidados de saúde pode ser compreendido enquanto uma política implícita ou explícita que restringe medidas específicas de cuidados de saúde, fundamentada pelo fato de que os custos são proibitivos para o sistema de saúde e a sociedade. O racionamento pode ser feito mediante a não incorporação de determinadas prestações de cuidados de saúde, por exemplo, reprodução assistida ou cirurgias estéticas. Ou, ainda, restringindo o acesso aos cuidados por idade, capacidade de pagamento ou vivência de estilos de vida considerados não-saudáveis, como se deu nos anos 90 na Inglaterra 6 .

Já a priorização dos cuidados de saúde é realizada mediante escolhas hierarquizadas entre alternativas de cuidados disponíveis, dentro dos limites de recursos do sistema, sem que haja restrições a priori orientadas por fatores ou critérios determinados.

No Brasil, poderíamos dizer que um racionamento não explícito é realizado pelo Congresso Nacional, Assembléias Estaduais e Câmaras Municipais ao aprovarem os respectivos orçamentos para o setor saúde. Já o estabelecimento de prioridades das políticas públicas de saúde e da distribuição dos recursos passa pelas decisões dos órgãos do Poder Executivo - Ministério e Secretarias Estaduais e Municipais de Saúde -, o aval dos órgãos de controle social, os Conselhos de Saúde e a negociação entre as autoridades sanitárias dos três níveis de governo, nas Comissões Bipartite e Tripartite.

Quanto à possibilidade de racionamento explícito de cuidados de saúde discriminando indivíduos ou grupos sociais por idade ou pela existência de estilos de vida não-saudáveis, como tem ocorrido em outros países, tal não é possível no Brasil, dentro da obediência dos termos legais vigentes, sem se alterar o princípio da universalidade de acesso ao sistema público de saúde. Isso colocaria em xeque a orientação constitucional de ser a saúde um direito de todos os cidadãos.

Todavia, é por demais reconhecido que as necessidades de saúde suplantam os recursos existentes. Que temos de fazer escolhas frente a dilemas e problemas de natureza ética. Assim sendo, se pode questionar quais seriam as alternativas de solução. Aumentar os recursos? No caso brasileiro posicionamo-nos favoravelmente a uma política de médio prazo que garanta mais recursos financeiros, além do pouco que é dispensado atualmente. O Brasil, segundo levantamento do Conselho Nacional de Secretários Municipais de Saúde (CONASEMS), em 2006 gastou em torno de 100 Dólares por habitante/ano, mediante verbas públicas provenientes das três esferas de governo, o que é pouco para se viabilizar o atendimento com qualidade a todos os cidadãos necessitados dos serviços prestados pelo Sistema Único de Saúde (SUS). 
A segunda alternativa seria a de dar mais eficiência aos gastos. Isso seguramente é um procedimento ético, pois recursos públicos devem obrigatoriamente ser aplicados com eficiência, além de serem efetivos. A validade científica e a perspectiva de sucesso de um procedimento constituem-se em critérios eticamente válidos, pois utilizar um recurso escasso sem se obter uma razoável chance de benefício seria um desperdício injusto.

A terceira alternativa, que não exclui as anteriores, é a do estabelecimento de prioridades na distribuição dos recursos existentes. E não é muito difícil de ser percebido que conforme as prioridades de uma política pública, estaremos, de uma maneira ou outra, levando a um racionamento de cuidados de saúde. Como exemplo, pode-se levantar a questão de que se priorizássemos as condições para o incremento da realização de transplantes ou de procedimentos de alto custo, seguramente outras ações e campos de saúde, como a atenção básica, poderiam ter seus recursos diminuídos.

Enfim, quais os critérios válidos eticamente para a tomada de decisão?

Neste artigo, queremos trazer uma breve reflexão sobre os possíveis conflitos entre os princípios éticos da utilidade social e da eqüidade no racionamento/priorização dos cuidados de saúde.

\section{Parâmetros éticos : utilidade social $x$ eqüidade}

A pergunta que inicialmente se coloca é: "Quais seriam os critérios éticos orientadores de uma boa e justa priorização de recursos referentes aos cuidados de saúde?" Pergunta que não é tão fácil ou simples de ser respondida, principalmente devido ao pluralismo de valores morais existentes na sociedade contemporânea, que levam a diferentes concepções do que seja uma ação boa e justa.

Uma das orientações éticas para se avaliar o que é justo é a dada pelo utilitarismo. As teorias utilitaristas defendem que para a avaliação da moralidade dos atos humanos se deva sempre levar em conta as conseqüências, os resultados das ações, se proporcionando o "maior bem-estar para o maior número possível de pessoas", ou seja, a maximização do bem-estar. Apesar das dificuldades de se conceituar o que é "bem-estar", isto pode significar que, quando são defrontadas duas ou mais opções, deverse-ia pesar cada uma delas e escolher aquela que trouxesse mais benefícios e na qual fossem eliminados, evitados ou minimizados o dano, o sofrimento, a dor, ou seja, tudo o que for considerado em oposição ao "bem", à "felicidade" do maior número de pessoas envolvidas ?.

Trazendo-se a reflexão do princípio utilitarista para as decisões de priorização de recursos públicos nos cuidados de saúde, pode-se dizer que o correto, o justo, seria priorizar aqueles que proporcionassem mais saúde ao maior número de pessoas. Seria a maximização do bem-estar ou da saúde geral. Exemplo simples a ser lembrado são as medidas de prevenção de doenças aportadas pelas medidas de vacinação em massa, que vêm tendo sucesso no controle e erradicação de várias doenças transmissíveis, tais como a varíola, a poliomielite, o tétano e o sarampo.

Se aceitarmos que o dever do administrador público é dar proteção às necessidades do coletivo, mesmo que às custas dos interesses individuais, as decisões deveriam ser condizentes com o princípio da utilidade social, validando a utilização de critérios como magnitude, força produtiva, transcendência, custos/benefícios.

Assim, nas condições sociais vigentes no país, políticas de saúde priorizando pessoas de menor rendimento econômico acatariam o princípio utilitarista, em virtude da grande magnitude de pessoas que vivem nestas condições. Todavia, o mesmo poderia não acontecer em uma outra sociedade em que os mais desafortunados do ponto de vista social não constituem a maioria da população, tais como os sem-teto em países desenvolvidos, como Estados Unidos e Canadá. Políticas para esses grupos, observadas do ponto de vista estritamente utilitarista, poderiam se contrapor a que fossem maximizados os benefícios dos recursos empregados.

No mesmo sentido, se as decisões são tomadas sob bases estritamente utilitaristas, elas podem ser contrárias à aplicação de recursos em atividades custosas, mas que dão baixa cobertura populacional, tais como transplantes, hemodiálise, distribuição de medicamentos de alto custo, e mesmo de anti-retrovirais para os HIV positivos e os aidéticos. Ou ainda, se poderia questionar se deveríamos, no sentido de diminuir as condições de pobreza dos cidadãos, investir mais no Estado de São Paulo do que no Estado do Maranhão, pois no primeiro há um maior contingente de pessoas pobres.

Portanto, pode-se dizer que a observância do princípio ético da utilidade social se oporia ao princípio ético da eqüidade?

Antes de a isso responder, precisamos esclarecer o significado do termo eqüidade. Eqüidade é um termo polissêmico, às vezes confundido com o termo igualdade. Porém, não é este o significado que utilizamos nem o mais corrente 
nas discussões sobre os sistemas e as políticas de saúde.

Uma das primeiras interpretações de eqüidade, que deriva do pensamento aristotélico, entende que as pessoas iguais deveriam ser tratadas igualmente e as desiguais deveriam ser tratadas desigualmente, segundo o princípio da proporcionalidade natural. Porém, para Aristóteles e seus seguidores, a diferenciação seria orientada pelo merecimento da pessoa frente à sociedade. Na sociedade grega, cidadãos livres, em seus direitos, eram diferenciados dos artesãos, dos estrangeiros e dos escravos. Homens eram hierarquicamente superiores, no merecimento, às mulheres.

Eqüidade em saúde é atualmente mais entendida como aceitando, não a igualdade, mas sim a diferença entre as pessoas em suas condições sociais e sanitárias, tendo necessidades diferenciadas. Assim, uma ação guiada pela eqüidade deveria proporcionar a cada pessoa a satisfação de suas necessidades, que são diferenciadas. Eqüidade pode ser considerada como " $a$ cada um conforme suas necessidades".

Todavia, nas últimas décadas do século $\mathrm{XX}$ popularizou-se o pensamento exposto por John Rawls 8, da justiça enquanto eqüidade. O filósofo defendeu ser justa a ação que tenha conseqüências desiguais para os diversos envolvidos apenas quando resultam em benefícios compensatórios para cada um, e particularmente para os membros "menos favorecidos", "menos afortunados" da sociedade. Sua teoria se contrapõe ao utilitarismo anglo-saxão. A eqüidade seria uma desigualdade aplicada a uma "boa causa", tendo uma função reparadora em minimizar os efeitos da loteria social, priorizando as necessidades dos "mais desfavorecidos".

Nunes 9 (p. 13), afirma que "a eleição dos mais necessitados é central na elaboração de qualquer metodologia que pretenda alocar ou alterar a alocação de recursos de modo mais eqüitativo. Políticas de alocação de recursos que se pretendam mais eqüitativas, devem ser avaliadas, em um primeiro momento, pela seleção das necessidades". Mas, quais necessidades?

Porém, sem nos delongarmos nos aspectos teóricos do pensamento de Rawls, uma questão pode ainda ser levantada. Quais as bases e critérios para se dizer que alguém é um desafortunado, um desfavorecido? Seriam bases e critérios econômicos, sociais, demográficos, epidemiológicos e sanitários ou critérios biológicos, relacionados a condições patológicas?

Se utilizarmos critérios estritamente biológicos, os mais desafortunados serão os "mais doentes", os "mais graves", ou ainda, os pacientes em fase terminal. Seria esta uma orientação desejá- vel? Estaríamos nos opondo à maximização dos benefícios? O filósofo e sanitarista francês Pierre Boitte ${ }^{10}$, com o qual concordamos, defende que se deva utilizar critérios sociais para o julgamento de quem seriam os mais necessitados, e não critérios biológicos, pois assim se atenderia aos princípios do pensamento de Rawls.

Cabe ainda lembrar que na década de 90 propalou-se na área de saúde a noção de eqüidade formulada por Whitehead 11, que a entende enquanto possibilidade de superação de desigualdades evitáveis e injustas. Para a autora, desigualdades injustas referem-se a comportamentos desfavoráveis à saúde em que a escolha individual é restrita. Mesmo assim, seguindo-se essa orientação, cabe ainda decidir o que se considera como "injusto".

Enfim, cada sociedade deve decidir se, em determinada situação, se orienta fundamentalmente pela eqüidade (e, qual eqüidade) ou por orientações mais utilitaristas.

Vejamos, como exemplo, o caso recente do Projeto de Lei do Senado no. 219/2007, apresentado pelo Senador Sebastião Viana, representante do Estado do Acre, em maio de 200712.

O projeto pretende alterar itens da Lei no. 8.080/90, conhecida como Lei Orgânica da Saúde, que dispõe sobre a organização e o funcionamento do SUS. Pretende limitar a assistência farmacêutica fornecida pelo SUS. Defende que a interpretação do conceito de integralidade da assistência farmacêutica seja referente àquilo que é constante nas tabelas e consoante às diretrizes terapêuticas instituídas pelo gestor federal do SUS. Veda o pagamento, o ressarcimento ou o reembolso de procedimentos experimentais, de medicamentos sem registro na Agência Nacional de Vigilância Sanitária (ANVISA).

Se o conteúdo do projeto for acatado e tornar-se norma legal, verificar-se-á o entendimento que a assistência farmacêutica no SUS deva ter uma orientação fundamentalmente de natureza utilitarista, com predomínio dos interesses coletivos sobre os individuais.

Entretanto, na prática das políticas públicas sanitárias no país as decisões de priorização de recursos, muitas vezes, mesclam os dois princípios - maximização dos benefícios (utilitarista) e eqüidade. Vejamos o caso do Programa Saúde da Família (PSF). A instalação dos serviços e unidades do PSF se dá, prioritariamente, nas áreas onde vivem pessoas em situação sócio-sanitária mais desfavorável. Isso significa uma decisão que intenta diminuir as desigualdades sociais e sanitárias, na linha da orientação pela eqüidade. Todavia, o Ministério da Saúde também preconiza que os recursos no PSF priorizem o diagnóstico precoce e intervenção para doenças como a dia- 
betes e a hipertensão arterial. Tal se dá porque uma ação dessa natureza tende a ser mais eficiente na prevenção de distúrbios cardiovasculares e renais, evitando desde infarto do miocárdio e acidentes vasculares cerebrais como a insuficiência renal crônica e a necessidade posterior de hemodiálise e até de transplantes, sendo, portanto, uma decisão essencialmente regida pelo princípio maximizador da utilidade social.

Como exemplo atual de aceitação de uma mescla de orientações - utilitarista e eqüitativa-, pode-se citar a linha atual da Bioética da Intervenção, desenvolvida fundamentalmente por bioeticistas da Cátedra UNESCO da Universidade de Brasília. Defende que a bioética em países periféricos, como os da América Latina, tenha como orientação a eqüidade para a diminuição das iniqüidades existentes. Todavia, em uma linha utilitarista, preconiza que " no campo público e coletivo: a priorização de políticas e tomadas de decisão que privilegiem o maior número de pessoas, pelo maior espaço de tempo e que resultem nas melhores conseqüências, mesmo que em prejuizo de certas situações individuais, com exceções pontuais a serem discutidas" 13 (p. 7).

\section{Finalizando}

A idéia de que a sociedade distribua bens escassos ou produtos entre os indivíduos que têm necessidades conflitantes é muito recente na história da humanidade. O conceito moderno de justiça distributiva, cujos fundamentos são provenientes do século XVIII, e o pré-moderno, são muito diferenciados. Este se baseava na idéia de mérito pessoal. Já o moderno demanda que o Estado intervenha e garanta a distribuição de bens para que as pessoas tenham suprido um determinado nível de interesses e recursos materiais 14 .

Contudo, as dificuldades do mundo contemporâneo em decidir eticamente sobre a distribuição de recursos escassos constituem uma das características mais marcantes de nossa época, que convive com um pluralismo moral, em que não mais são aceitos valores considerados como sendo absolutos e coexistem diferentes princípios e valores que muitas vezes se tornam incompatíveis entre si, como por exemplo, o individualismo e a solidariedade.
Será então possível serem estabelecidas formas consensuais para a solução dos problemas e dilemas éticos contemporâneos? É possível que possamos chegar a consensos sobre a questão da justiça distributiva e distribuição justa de recursos?

Escolhas têm de ser feitas, e devem ser de responsabilidade dos gestores e dos cidadãos, manifestando-se por meio dos instrumentos democráticos existentes. Não cabe a decisão ser somente dos profissionais de saúde, que têm com aqueles aos quais se vinculam diretamente uma relação estabelecida na confiança, na beneficência e na não maleficência, além do respeito às decisões autônomas 15,16.

Entendemos que uma justa priorização de recursos deva ser explícita, aprimorando as formas de participação real da comunidade nas decisões a serem tomadas, sobretudo quando os recursos forem escassos ou limitados. E, apesar de se poder concordar que não é fácil descobrir os valores da maioria dos membros de uma comunidade, pode-se também concordar com Karl Popper, quando afirma que a presença da representação da comunidade é o único processo, por mais falível que seja, que se tem à disposição para se chegar a algum consenso sobre o problema 17 .

No Brasil, está ocorrendo a prática de utilização de mecanismos de controle social institucionalizado, como os Conselhos de Saúde, que devem possibilitar a ampliação de uma ação dialógica envolvendo os diversos atores sociais no campo da saúde, explicitando conflitos de interesses e de valores, buscando a constituição de possíveis consensos em dilemas e problemas éticos. Apesar das críticas e desilusões com esses instrumentos, pode-se ainda afirmar que o exercício democrático de que todos os segmentos sociais interessados em um determinado campo social, tal qual o campo da saúde, aceitos como interlocutores válidos, ouvidos e podendo influenciar a tomada de decisão, possa resultar em acordos satisfatórios e prudenciais para os diversos segmentos representados nestas difíceis matérias 2 .

Enfim, a reflexão bioética pode auxiliar na maximização do consenso sobre normas práticas que dizem respeito à vida e à saúde da espécie humana, construindo a convivência da vida em sociedade 18 . 


\section{Resumo}

Sendo as necessidades de saúde mais amplas que os recursos disponíveis, escolhas têm de ser feitas. Disto resulta ser preciso que se estabeleçam limites, critérios e parâmetros para priorizar o que vai ser ofertado e a quem os serviços e os cuidados de saúde serão oferecidos. Discute-se alternativas éticas para a priorização e racionamento de cuidados de saúde, enfocando os princípios da eqüidade e da utilidade social.

Bioética; Alocação de Recursos; Eqüidade em Saúde

\section{Referencias}

1. Basson MD. Choosing among candidates for scarce medical resources. J Med Philos 1979; 4:313-33.

2. Cortina E, Martinez E. Ética. São Paulo: Edições Loyola; 2005.

3. Schramm FR. Da bioética privada à bioética pública. In: Fleury S, organizadora. Saúde e democracia: a luta do CEBES. São Paulo: Lemos Editorial; 1997. p. 227-40.

4. Pessini L, Barchifontaine CP. Problemas atuais de Bioética. 5a Ed. São Paulo: Centro Universitário São Camilo/Edições Loyola; 2000.

5. Momberg JM. Políticas de salud: ética en la asignación de recursos. In: Calvente MMG, organizadora Ética y salud. Granada: Escuela Andaluza de Salud Pública; 1998. p. 77-87.

6. British Medical Association. Medical ethics today: its practice and philosophy. London: BMJ Publishing Group; 1997.

7. Mill JS. O utilitarismo. São Paulo: Editora Iluminuras; 2000.

8. Rawls J. Uma teoria da justiça. São Paulo: Editora Martins Fontes; 1997.

9. Nunes A. A alocação eqüitativa inter-regional de recursos públicos federais do SUS: a receita própria do município como variável moderadora. Brasília: Sistema de Informações sobre Orçamentos Públicos em Saúde, Departamento de Economia da Saúde, Secretaria de Ciência, Tecnologia e Insumos Estratégicos, Ministério da Saúde; 2004.

10. Boitte P. Ethique, justice et santé: allocation des ressources en soins dans une population vieillisante. Brussells: Artel/Montreal: Fides; 1995.
11. Whitehead M. The concepts and principles of equity and health. Copenhagen: World Health Organization; 1991.

12. Senado Federal. Projeto de lei do Senado no. 219 , de 2007. Altera a Lei $n^{\circ}$. 8.080, de 19 de setembro de 1990, para dispor sobre a oferta de procedimentos terapêuticos e a dispensação de medicamentos pelo Sistema Único de Saúde (SUS). http://pfdc. pgr.mpf.gov.br/informativos-pfdc/edicoes-2007 (acessado em 10/Set/2007).

13. Garrafa V, Porto D. Bioética, poder e injustiça; por uma ética de intervenção. Mundo Saúde 2002; 26:6-15.

14. Fleischacker S. Uma breve história da justiça distributiva. São Paulo: Editora Martins Fontes; 2006.

15. Gracia-Guillén D. Ética, salud y servicios sanitarios. In: Calvente MMG, organizadora. Ética y salud. Granada: Escuela Andaluza de Salud Pública; 1998. p. 11-24.

16. Veatch RM. Healthcare rationing through global budgeting: the ethical choices. J Clin Ethics 1994; 5:291-6.

17. Charlesworth M. La bioética en una sociedad liberal. New York: Cambridge University Press; 1996.

18. Boff L. Ethos mundial: um consenso mínimo entre os humanos. Rio de Janeiro: Editora Sextante; 2003.

Recebido em 17/Out/2007 Aprovado em 10/Jan/2008 